\title{
Establish high-resolution hourly weather data for simulating building energy consumption in different regions
}

\author{
Feng-Yi Lin ${ }^{1, *}$, Ruey-Lung Hwang ${ }^{2}$, and Tzu-Ping Lin ${ }^{1}$ \\ ${ }^{1}$ Department of Architecture, National Cheng Kung University, Taiwan \\ 2 Department of Industrial Technology Education, National Kaohsiung Normal University, Taiwan
}

\begin{abstract}
Due to the various local weather conditions in different regions of the city, the demand for air conditioning (AC) of housing is different, too. It happened occasionally to underestimate the energy consumption of AC in urban areas, because of using suburban/rural weather station data for building energy simulation. This study set up 34 automatic weather stations in the urban area of Tainan City, Taiwan for a year-round collection of local temperature and relative humidity data. Those weather measurement, the GIS information of a buffer zone and multiple regression analysis were used to establish the relationship between the weather factors, needed for the morphing approach, and the parameters of landscape use and cover. The buffer zone is an area of $1000 \times 1000 \mathrm{~m}^{2}$ around the measured point, and is divided to two layers with upwind and downwind parts. Local hourly weather-year files for a whole of the city with a resolution of $200 \times 200 \mathrm{~m}^{2}$ were generated by the morphing approach. With the different local hourly weather-year files, the AC-required hours and energy consumption from May to October for a typical residential with hybrid ventilation mode was obtained by using the EnergyPlus. And the cumulative UHI of each grid between May and October is calculated by taking the average of the five lowest temperatures as the reference value. The result shows that the number of $\mathrm{AC}$ hours of residential will increase by $10 \%$, and the energy consumption increase from 1000 $\mathrm{kWh}$ to $2500 \mathrm{kWh}$, when long-term UHI intensity increases from $2000{ }^{\circ} \mathrm{C}$-hour to $9000^{\circ} \mathrm{C}$-hour.
\end{abstract}

\section{Introduction}

The concentration of population in urban areas intensifies the urban heat island effect (UHI), which causes the greater temperature difference between urban and suburb areas. As the temperature in urban areas rises, urban residents' dependence on air conditioning (AC) is higher than that of residents in suburbs. Many research projects have proven that the energy consumption of AC in urban areas surpasses that in suburb areas. For example, such differentiation is $8 \%$ in Singapore [1], 46\% in Rome, Italy [2]; 32-42\% in City of London, United Kingdom [3]; $18-28 \%$ in Barcelona, Spain [4]; 23-46\% in the CBD of Melbourne, Australia [5]; and 10\% in Beijing [6] and Hong Kong [7].

In the past, to analyze the energy consumption differences between urban and suburban areas, most researchers choose a building in the urban and the suburb to compare the energy consumption difference between the two, or used weather stations data to simulate the energy consumption differences between urban and suburban areas. However, most weather stations are located in open areas, and it is easy to underestimate the air conditioning energy consumption in urban center when evaluated by a single weather station. On the other hand, it was difficult for a single weather station to detect the energy consumption differences between the large urban and suburban areas. The most ideal method is to obtain the real-time information on energy consumption of buildings in different urban areas, but it is not easy to obtain such information. Therefore, most studies adopted simulation to evaluate the building energy consumption in urban areas. To further analyze the energy consumption differences between the whole urban and suburban areas, the local hourly weather data of different areas is required for large-scale energy simulation.

Therefore, the purpose of this study is to integrate the local hourly weather data of urban areas, use the data to simulate residential energy consumption, and probe into the impact of urban microclimate on energy consumption.

\section{Method}

\subsection{Research subjects and models}

This study used EnergyPlus as a simulation tool to simulate residential energy consumption in different urban areas, aiming to learn about the impact of different types of urban topology on residential AC energy consumption. During the simulation, since the hourly weather data should serve as a response to the building's thermal load and energy consumption, the hourly weather data of areas was needed. Thus, this study divided the core area of Tainan City, Taiwan into 1,496 square meshes with the size of $200 \mathrm{~m} \times 200 \mathrm{~m}$, as shown in Figure 1 . The

\footnotetext{
* Corresponding author: fusm60uds@gmail.com
} 
hourly weather data of each mesh simulated the residential energy consumption in different areas.

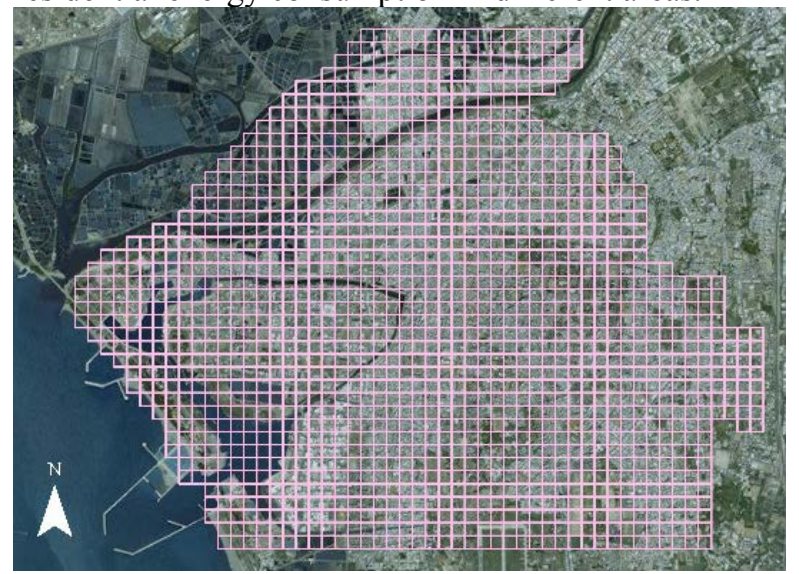

Fig. 1. Research scope and methods for mesh division.

The simulation model is a common three-story town house with a coverage of $102.6 \mathrm{~m}^{2}$ in Tainan. The number of rooms and the position of windows are shown in Figure 2. The shading depth is $40 \mathrm{~cm}$, the number of users is 4 , the luminance density is $10 \mathrm{~W} / \mathrm{m}^{2}$, and the total equipment load is $15 \mathrm{~W}$. The ventilation mode is hybrid ventilation, which is a mixture of $\mathrm{AC}$ and natural ventilation. The upper limit acceptability of $80 \%$ recommended by ASHRAE Standard 55 was used to determine whether natural ventilation or $\mathrm{AC}$ was used.

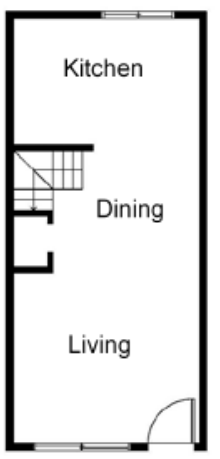

$1 \mathrm{~F}$

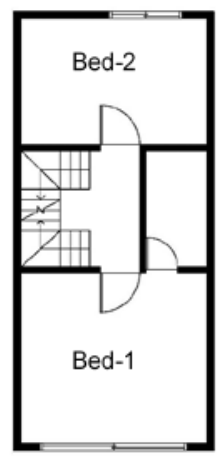

$2 \mathrm{~F}$

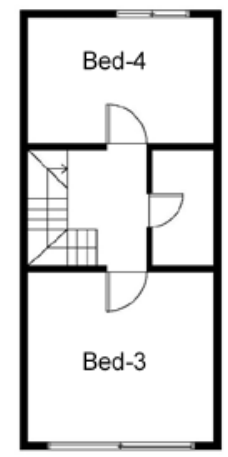

$3 \mathrm{~F}$
Fig. 2. Plan view of the house for simulation.

\subsection{Integration of local hourly weather data}

To formulate the local hourly weather data of each mesh in Tainan, this study used the Morphing approach developed by Belcher et al. [6]. The official weather stations in Tainan served as the basis for calculation. The data obtained by 34 air temperature and relative humidity recording stations set up by Lin et al. [7] from April 2016 to March 2017 was used as the basic database. Using 1) a shift; 2) a linear stretch; and 3) a shift and a stretch of Morphing approach to generate the annual hourly temperature and relative humidity at any location. The calculation method is shown in Eqs.(1)-(3).

$$
T=T_{0}+\Delta T_{m}+\alpha T_{m}\left(T_{0}-T_{0, m}\right)
$$

$$
\begin{aligned}
& \alpha T_{m}=\frac{\Delta T_{\max , m}-\Delta T_{\min , m}}{T_{0, \max , m}-T_{0, \min , m}} \\
& R H=R H_{0} \times\left(1+\alpha R H_{m}\right)
\end{aligned}
$$

where, $\mathrm{T}$ and $\mathrm{T}_{0}$ are the hourly temperatures of the city and baseline point respectively. $\mathrm{T}_{0, \mathrm{~m}}, \mathrm{~T}_{0, \mathrm{~min}, \mathrm{~m}}$, and $\mathrm{T}_{0 \text {,max,m, }}$ are respectively the monthly mean value of the air temperature, the monthly mean value of the daily maximum temperature, and the monthly mean value of the daily minimum temperature of the baseline point in the month of m. $\Delta \mathrm{T}_{\mathrm{m}}, \Delta \mathrm{T}_{\text {max,m }}, \Delta \mathrm{T}_{\text {min,m }}$ are respectively the difference of the monthly mean value of the air temperature, the monthly mean value of the daily maximum temperature, and the monthly mean value of the daily minimum temperature in urban areas and those in the baseline position. $\mathrm{RH}$ and $\mathrm{RH}_{0}$ are the hourly relative humidity of the city and the baseline position; $\alpha \mathrm{RH}_{\mathrm{m}}$ is the ratio of the monthly variation of the relative humidity of the city to the figure of the baseline position.

Due to the limited manpower and cost, it was impossible to set up temperature and relative humidity measurement stations in each mesh. Therefore, the important parameters of the Morphing approach such as $\Delta \mathrm{T}_{\mathrm{m}}, \alpha \mathrm{T}_{\mathrm{m}}$ and $\alpha \mathrm{RH}_{\mathrm{m}}$ needed to be predicted from building area, road area and green and water area obtained from the Geographic information system (GIS). These factors were screened through forward selection of Stepwise Regression. With the verification by root-mean square-error and index-of-agreement [7], Eqs. (4)-(6) show the regression results. The range of the predictive formula took into account the distance between the surroundings and the central observation point, as well as the prevalent wind direction. The square mesh covers an area of $1000 \times 1000 \mathrm{~m}^{2}$ and is divided into two layers, each of which is divided into upwind and downwind parts (4 levels in total). The square mesh of $200 \mathrm{~m} \times 200 \mathrm{~m}$ is the basic unit.

$$
\begin{gathered}
\alpha T_{m}=f(\text { Building, Road, Green \& Water }) \\
\Delta T_{m}=f(\text { Building, Road, Green \& Water }) \\
\alpha R H_{m}=f(\text { Building, Road, Green \& Water })
\end{gathered}
$$

\subsection{Urban heat island}

Most studies used the maximum difference between urban and suburban baseline temperatures to quantify UHI intensity (UHII). However, in order to evaluate the long-term differences of UHII in different locations, this study used the UHII indicators proposed by Cui et al. [8] and Dean [9]. The cumulative UHII indicators, in unit of ${ }^{\circ} \mathrm{C}$-hour, of a certain period defined by Eq. (7) describes the distribution of the urban heat island.

$$
U H I I=\sum_{h=1}^{H}\left[T_{k, h}-\min \left(T_{k, h}, T_{r, h}\right)\right]
$$


where $\mathrm{T}_{\mathrm{k}, \mathrm{h}}$ is the temperature of the $k$ mesh at the hour of $h \mathrm{~T}_{\mathrm{r}, \mathrm{h}}$ is the average temperature of the five meshes with the lowest temperature at the hour of $h . H$ is the total number of hours for a specified period.

\section{Result}

\subsection{Distribution of UHII}

Based on the impact of UHII on energy consumption of $\mathrm{AC}$, this study selected the period with the greatest temperature difference between urban areas of Tainan from May to October (hot season) to analyze, which is also the periods when $\mathrm{AC}$ is frequently used. Figure 3 shows the distribution of UHII in Tainan from May to October. During this period, UHII of $3 \%$ of meshes is between 8,000 to $9,500{ }^{\circ} \mathrm{C}$-hour; and UHII of $22 \%$ of meshes is between 6,500 to $8,000{ }^{\circ} \mathrm{C}$-hour. Both of these areas are of high building density in Tainan, resulting in high UHII. Approximately $49 \%$ of UHII in this area is between 3,500 to $6,500{ }^{\circ} \mathrm{C}$-hour, which is mainly affected by two factors: first, the new urban planning and design that slightly reduces the building density; second, the University Town with low building density, and a large amount of green space and vacant areas. All meshes with UHII below $3,500^{\circ} \mathrm{C}$-hour have large areas of green space and waters located in the suburbs.

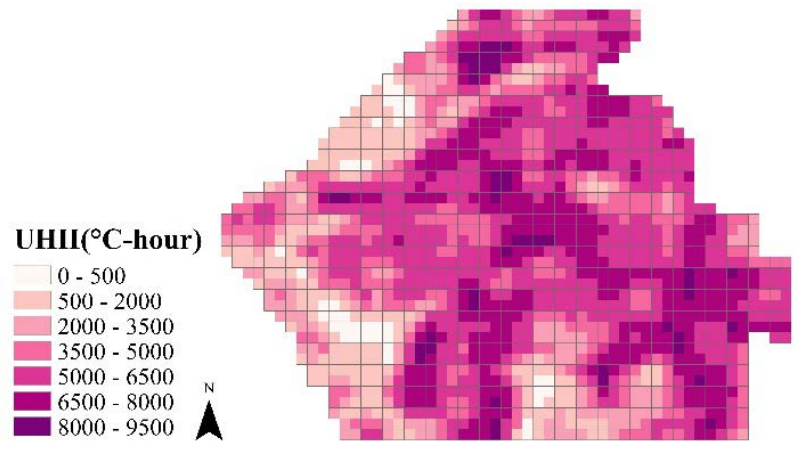

Fig. 3. UHII distribution.

\subsection{Distribution of AC energy consumption}

The weather data generated by each mesh was used to simulate the standard residential AC in different areas of Tainan. Figure 4 (A) shows the distribution of the total AC energy consumption (EU) in Tainan during the hot season. Figure 4 (B) displays the proportion of each energy consumption interval. According to the results, the energy consumption of AC in Tainan during hot seasons are $400-2,500 \mathrm{kWh}$. These results show that $8 \%$ of the urban areas register the AC energy consumption over $2,200 \mathrm{kWh}$, while $80 \%$ of the urban areas register that between 1,300 and 2,200 kWh. Only $12 \%$ of the suburbs register the AC energy consumption below $1,300 \mathrm{kWh}$.
Figure 5 shows the daily energy consumption difference between the meshes with respectively the highest and lowest energy consumption from May to October. The AC energy consumption difference is 0$19 \mathrm{kWh}$, and the average difference is $10 \mathrm{kWh}$. Among them, the mid-May was affected by continuous raining, and September saw a string of typhoons, so the AC energy consumption in these two periods was also less than that in other months.

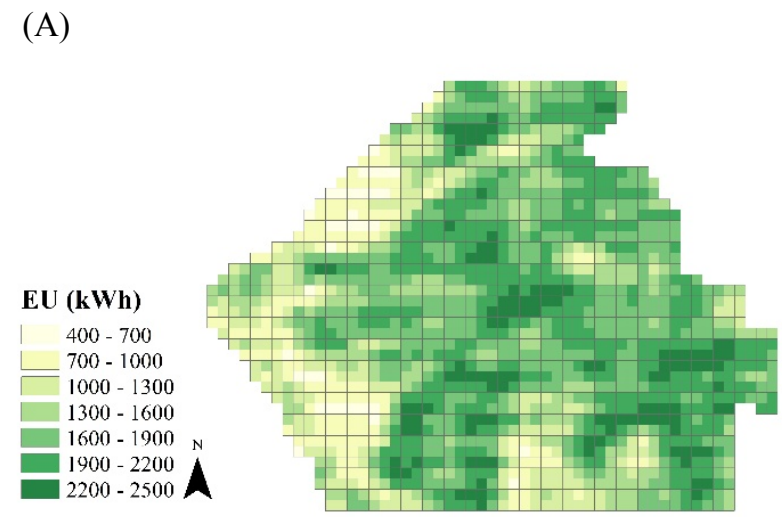

(B)

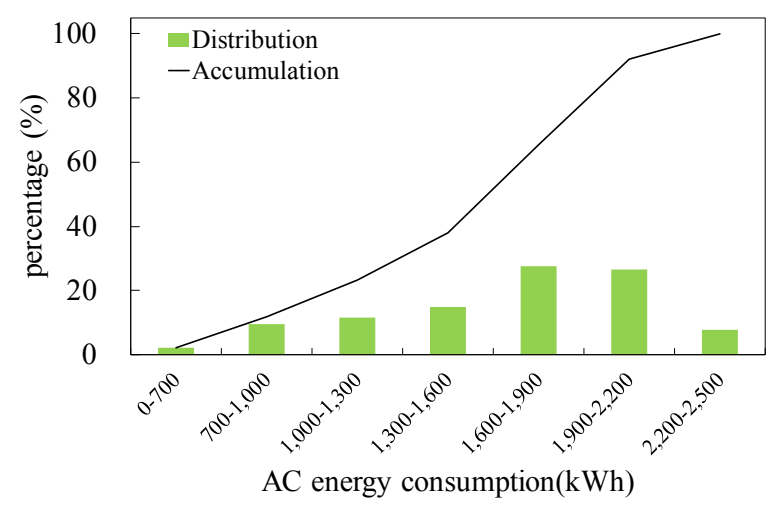

Fig. 4. Proportion of AC energy consumption (EU) (A) distribution and (B) proportion.

\subsection{Correlation between UHII and AC energy consumption}

Figure 6 (A) shows the total AC energy consumption and UHII accumulated from May to October in each mesh. Figure 6 (B) shows the ratio of UHII to the number of hours required for AC. According to Figure 6(A) and (B), the total energy consumption of $\mathrm{AC}$ in suburban areas (UHII $<3500{ }^{\circ} \mathrm{C}$-hour) is less than $1,300 \mathrm{kWh}$, and from May to October at most $40 \%$ of the period requiring AC. When UHII rises for $2,000{ }^{\circ} \mathrm{C}$-hour in urban center, the $\mathrm{AC}$ energy consumption increases by $500 \mathrm{kWh}$, and the proportion of hours requiring $\mathrm{AC}$ increases by $10 \%$. When UHII reached $8,000{ }^{\circ} \mathrm{C}$-hour, $\mathrm{AC}$ is required in nearly $70 \%$ of the period.

\section{Conclusion}




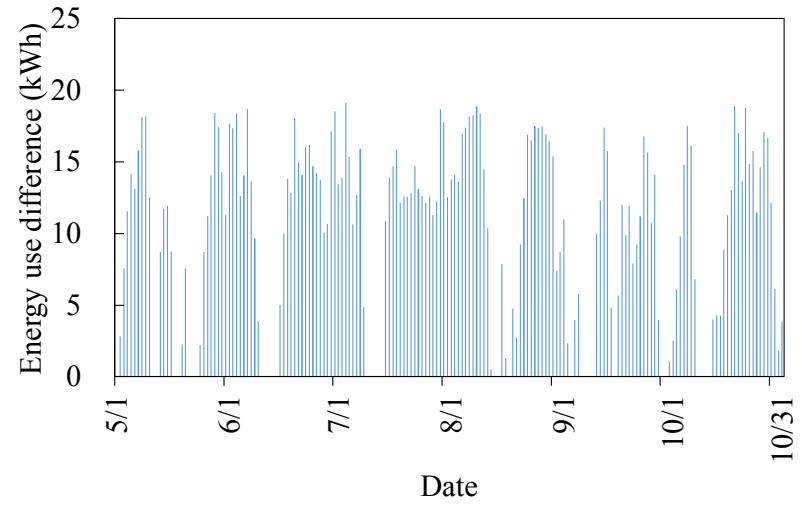

Fig. 5. Daily energy consumption difference between meshes with the highest and lowest energy consumption.
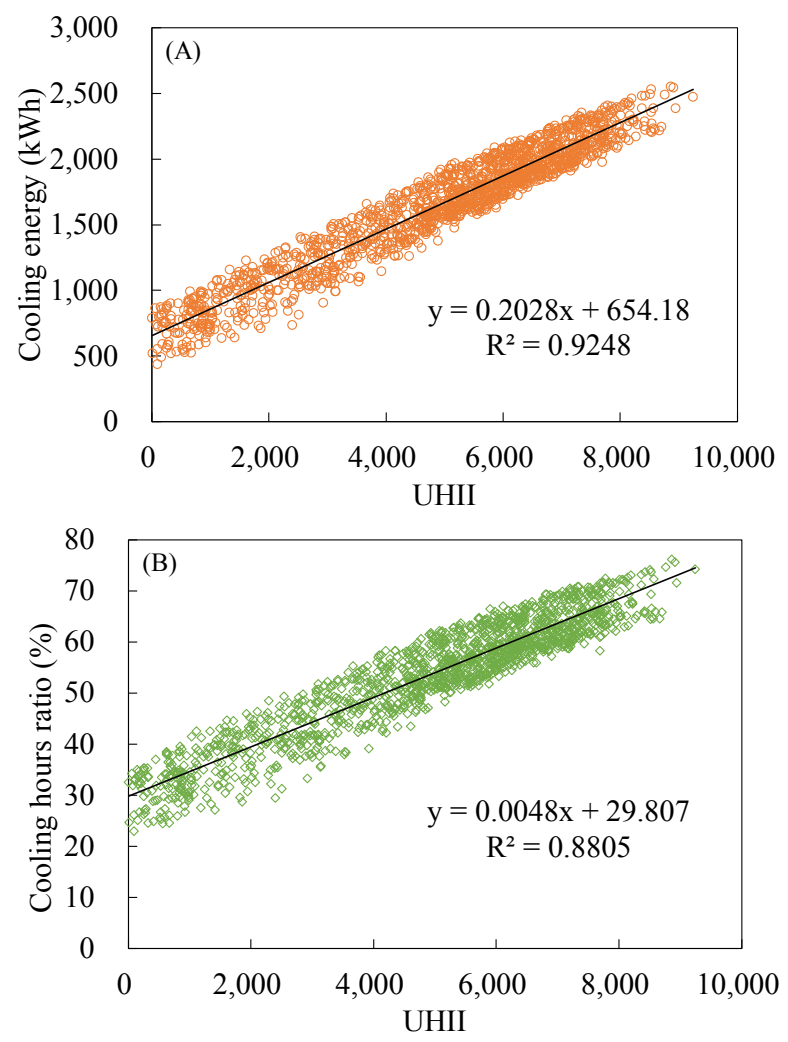

Fig. 6. Impact of UHII on AC energy consumption (A) and the number of hours requiring $\mathrm{AC}(\mathrm{B})$.

It is crucial to understand the energy consumption of different urban areas when the urban temperature is gradually increasing and the residents are more dependent on AC. Based on the data of air temperature and relative humidity and the information of GIS in Tainan city center, this study established the multivariate regression prediction of $\Delta \mathrm{T}_{\mathrm{m}}, \alpha \mathrm{T}_{\mathrm{m}}$ and $\alpha \mathrm{RH}_{\mathrm{m}}$. According to the hourly weather data of each mesh generated by the Morphing approach, the energy consumption of AC in standard residential buildings was simulated by using EnergyPlus. Finally, the hottest period of the year, namely from May to October, was selected for discussion. The results of this study lead to the following conclusions:
1. UHII in suburban areas is $3,500<{ }^{\circ} \mathrm{C}$-hour. UHII of $49 \%$ of suburban areas is $3,500-6,500{ }^{\circ} \mathrm{C}$-hour. UHII of areas with high construction density is above $6,500^{\circ} \mathrm{C}$-hour.

2. The energy consumption of $\mathrm{AC}$ in Tainan during the hot season is 400-2,500 $\mathrm{kWh}$. The energy consumption of $\mathrm{AC}$ in residential areas with high energy consumption is approximately $1,200 \mathrm{kWh}$ more than that in residential areas with low energy consumption.

3. For every $2,000{ }^{\circ} \mathrm{C}$-hour increase of UHII in the urban center, the total energy consumption of $\mathrm{AC}$ in residential buildings will increase by $500 \mathrm{kWh}$, and the proportion of hours requiring $\mathrm{AC}$ will increase by $10 \%$.

\section{Acknowledgement}

The authors offer their sincere appreciation for assistance in grant to the Ministry of Science and Technology, Taiwan, under Project no. MOST 106-2221-E-017 -013 MY2

\section{References}

1. Ignatius, M., Wong, N. H., \& Jusuf, S. K. The significance of using local predicted temperature for cooling load simulation in the tropics. Energy Build. 118, 57-69 (2016).

2. Zinzi, M., \& Carnielo, E. Impact of urban temperatures on energy performance and thermal comfort in residential buildings. The case of Rome, Italy. Energy Build. 157, 20-29 (2017).

3. Kolokotroni, M., Davies, M., Croxford, B., Bhuiyan, S., \& Mavrogianni, A. A validated methodology for the prediction of heating and cooling energy demand for buildings within the Urban Heat Island: Casestudy of London. Sol. Energy. 84, 2246-2255 (2010).

4. Salvati, A., Roura, H. C., \& Cecere, C. Assessing the urban heat island and its energy impact on residential buildings in Mediterranean climate: Barcelona case study. Energy Build. 146, 38-54 (2017).

5. Chen, D., Ren, Z., Wang, C. H., Thatcher, M., \& Wang, X. Urban Heat Island on Australian Housing Energy Consumption. 10th Int. Conf. Heal. Build. (2012).

6. Belcher, S., Hacker, J., Powell, D. Constructing design weather data for future climates. Build. Serv. Eng. Res. Technol. 26, 49-61 (2005).

7. Lin F.Y., Huang K.T., Lin T.P., \& Hwang R.L. (in press). Generating hourly local weather data with high spatially resolution and the applications in bioclimatic performance. Sci. Total Environ.

8. Cui, Y., Yan, D., Hong, T., \& Ma, J. Temporal and spatial characteristics of the urban heat island in Beijing and the impact on building design and energy performance. Energy. 130, 286-297 (2017). 
9. Dean, W. Creating and Mapping an Urban Heat Island Index for California, Altostratus Inc. Martinez, California. (2015). 